\title{
Causal Agent of Red Stripe Disease of Rice
}

F. A. Elazegui and N. P. Castilla, Entomology and Plant Pathology Division, International Rice Research Institute, DAPO Box 7777, Metro Manila, Philippines; T. U. Dalisay, Department of Plant Pathology, University of the Philippines at Los Baños, College, Laguna, Philippines; and T. W. Mew, Entomology and Plant Pathology Division, International Rice Research Institute, DAPO Box 7777, Metro Manila, Philippines

\begin{abstract}
Elazegui, F. A., Castilla, N. P., Dalisay, T. U., and Mew, T. W. 2004. Causal agent of red stripe disease of rice. Plant Dis. 88:1310-1317.

A variety of methods that included natural and synthetic media for isolating bacteria and fungi were used to isolate the causal agent of the red stripe disease of rice. A fungus was isolated consistently from leaves with red stripe symptoms using the blotter method. In this method, surfacesterilized leaves were placed on sterile petri plates, lined with moistened filter paper, and the plates were incubated for 14 days at 28 to $30^{\circ} \mathrm{C}$. The fungal isolate was reisolated from the lesions of inoculated plants and reinoculated on test plants that became symptomatic, thus fulfilling Koch's postulates. Based on the morphological characteristics of the fungus, the causal agent of red stripe was identified as a species of Gonatophragmium. Colonies of the latter are slowgrowing, reaching an average of $29.0 \pm 0.9 \mathrm{~mm}$ in diameter after incubation on potato dextrose agar (PDA) for 18 days at 28 to $30^{\circ} \mathrm{C}$ in the dark. It can be overgrown easily by saprophytes when infected leaves are incubated using the blotter method without sterilization. Yellow-orange pigmentation was observed on PDA with mycelial growth and on filter paper with infected leaves, a unique characteristic which facilitates the isolation of the fungus. Studies are in progress using traditional and molecular techniques to identify the pathogen to the species level.
\end{abstract}

Additional keywords: blotter method, Dematiaceae, etiology

Red stripe, an emerging disease of rice, has been observed in recent years in intensive rice-production systems in tropical Asia. It also is known in Vietnam as yellow leaf disease (12), yellow leaf syndrome (21), and leaf yellowing syndrome (20), and in Indonesia as bacterial orange leaf blight (19). It was first reported in Indonesia in 1987 (15), and later in Cambodia (6), Laos (6), Malaysia (18), Philippines (2), Thailand (3), and Vietnam $(5,21)$. It occurs sporadically in these countries, except in Vietnam, where farmers in the Mekong Delta consider it an important disease problem (12). The etiology of the disease is uncertain, which can be attributed partly to the difficulty in isolating and identifying the causal agent. Consequently, the epidemiology of the disease is not well understood.

Typical red stripe symptoms observed in the field are unbordered, yellow-orange spots with streaks that advance toward the leaf tips (Fig. 1A and B). Although more common on the leaf blades, lesions also

Corresponding author: T. W. Mew

E-mail: t.mew@cgiar.org

First and second authors contributed equally to this research.

Accepted for publication 20 July 2004.

Publication no. D-2004-1014-01R

(C) 2004 The American Phytopathological Society are found on the leaf sheaths and culms. In the field, typical symptoms usually are observed from flowering to ripening stages of rice development. The symptoms do not resemble those of any other rice diseases; therefore, various attempts have been made to establish the etiology of the disease. The fungus Curvularia lunata (5) and bacteria such as Acidovorax avenae subsp. avenae (20) and an unknown species of Microbacterium (9) were reported to be associated with the disease. However, there has been no conclusive evidence that any of these organisms produce typical red stripe symptoms under natural or controlled conditions. Various studies have provided circumstantial evidence that red stripe may be caused by a fungus. For example, Du et al. (4) reported that red stripe intensity was lower in fields sprayed with benzimidazole fungicides, especially benomyl and carbendazim, compared with unsprayed fields. Greenhouse experiments conducted at the International Rice Research Institute (IRRI) also showed that plants sprayed with benzimidazole fungicides had lower disease severity than those sprayed with other groups of fungicides and bactericides (N. P. Castilla, F. A. Elazegui, and T. W. Mew, unpublished). Various studies and issues related to the establishment of the etiology of red stripe recently were reviewed (14) to provide baseline information that may facilitate the isolation of the causal agent.
This article reports the results of studies demonstrating that red stripe is caused by a fungal pathogen. We describe the methods used to isolate the causal agent, test its pathogenicity, and reisolate it from the lesions of inoculated plants to fulfill Koch's postulates.

\section{MATERIALS AND METHODS}

Collection of infected leaves. Leaves showing typical red stripe symptoms were collected from naturally infected rice plants in farmers' fields in Isabela and Cagayan Provinces, Philippines, in 2000 and 2002. Diseased leaves were collected from modern cultivars that included IR72, IR64, PSBRc18, and PSBRc28. Leaves were moistened, placed in plastic bags, and kept in buckets with ice during transport from the collection site to the laboratory at IRRI. Isolations were made within $48 \mathrm{~h}$ of collecting the leaves.

Isolation of fungi. The first method used for isolating fungi was tissue plating on various culture media. In this method, sections of 2 to $5 \mathrm{~mm}$ were cut from the margin of leaf lesions. Leaf sections were surface sterilized in $2.5 \%$ ( vol/vol) sodium hypochlorite for $15 \mathrm{~s}$, rinsed once in sterile distilled water, and blotted dry on a sterile paper towel. Leaf sections were placed on different natural and synthetic culture media amended with $5 \%$ (vol/vol) lactic acid to inhibit bacterial growth. During the course of this study, red stripe lesion types were defined and, for each culture medium, 10 to 15 plates for each of the four types were prepared. The culture media tested were carrot agar, carrot juice agar, carrot leaf-decoction agar, carrot leaf-oatmeal agar, Czapek-Dox agar, Czapek-Dox V8 juice agar, Leonian agar, malt extract agar, malt-extract-dextrosepeptone agar, malt and yeast extract agar, modified Wakimoto's medium (10), oatmeal agar, potato-carrot agar, potatodextrose agar (PDA), potato-sucrose agar, prune agar (PA), rabbit food agar, rice polish agar, sucrose-peptone agar, V8 juice agar, and yeast extract-dextrose agar (YEDA). The culture plates were incubated for 14 days at 28 to $30^{\circ} \mathrm{C}$ in the dark and examined every 2 to 3 days for fungal growth. After 7 and 14 days of incubation, each distinct fungal colony was subcultured on PDA, PA, modified Wakimoto's medium, and YEDA and incubated for another 14 to 21 days. PDA, 
YEDA, and PA were selected because most fungal isolates appeared to grow well on these media. Fungal isolates with mycelial characteristics different from most of the media tested were observed on modified Wakimoto's medium.
The second method employed was the blotter method commonly used in routine seed health tests (13). In this method, sections of 5 to $10 \mathrm{~mm}$ were cut from the margin of leaf lesions. Leaf sections then were surface sterilized as described in the first method. Four to five leaf sections were placed on a sterile petri plate lined with filter paper moistened with sterile distilled water. The plates were incubated for 21 days at $30^{\circ} \mathrm{C}$ in the dark and examined for the presence of fungal growth
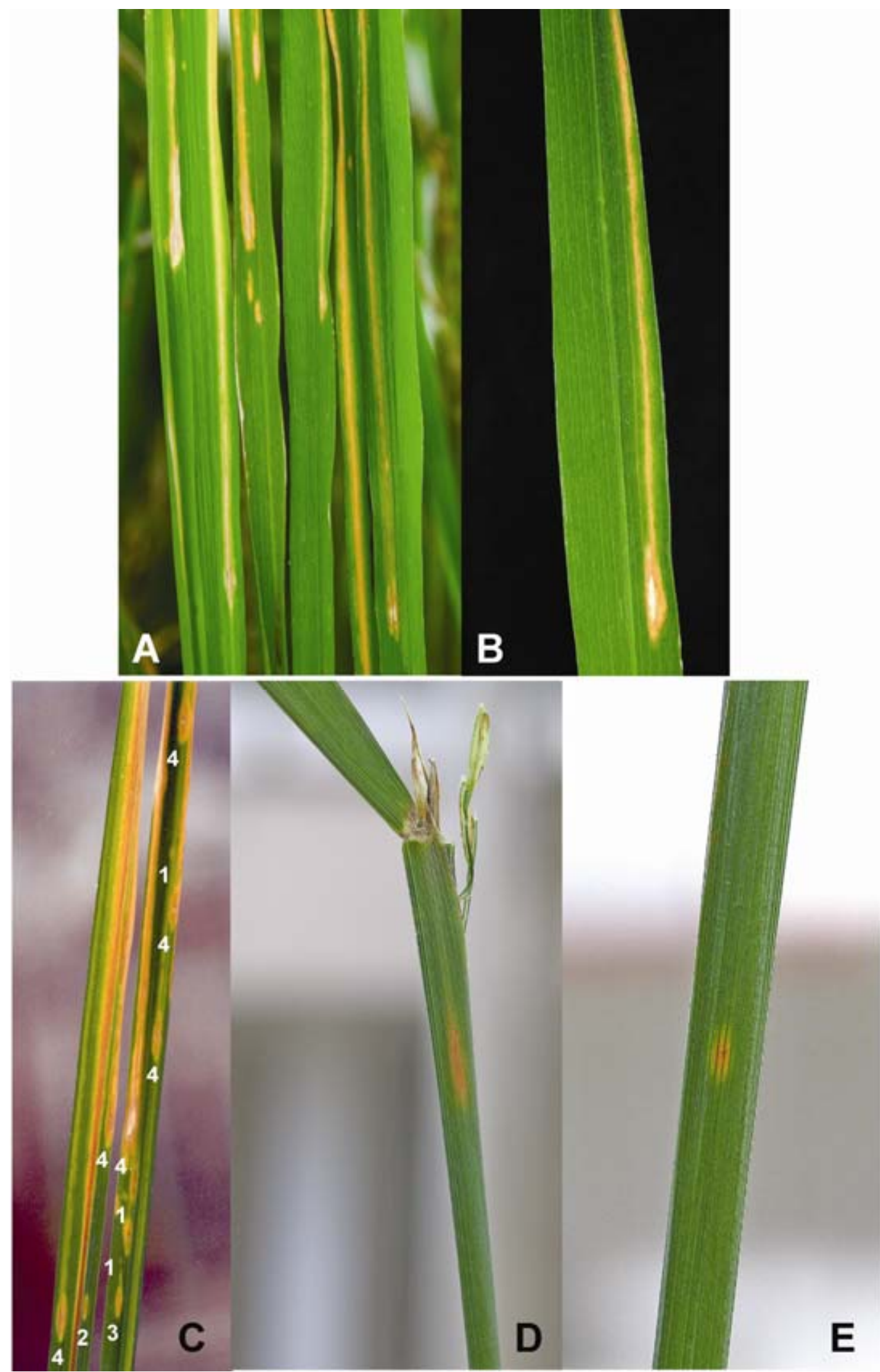

Fig. 1. Symptoms of red stripe. A, Typical symptoms in the field. B, Close-up of a typical symptom in the field. C, D, and $\mathbf{E}$, Lesions on the leaves, sheath, and culm, respectively, of a plant inoculated with isolate PRS37. Number written below a lesion on the leaf refers to the lesion type. 
from 3 to 14 days after incubation. Conidia of the developing fungus were picked individually by using sterile, glass capillary tubing and transferred to both PDA and water agar plates.

For both methods, 7-mm-diameter disks was cut from the end of a 7-day-old colony and placed on PDA slants. A visually distinct colony was designated as an isolate. The PDA slants were kept at $5^{\circ} \mathrm{C}$ in the dark until further use. These cultures were used for subsequent tests.

Pathogenicity tests for fungal isolates. Fresh cultures were established for pathogenicity testing by transferring stored cultures to plated PDA and incubating at 28 to $30^{\circ} \mathrm{C}$ in the dark for 7 days. Each isolate had four replicate plates. Fungal colonies then were gently scraped using a sterile glass slide and exposed to cycle of $12 \mathrm{~h}$ of near-ultraviolet (near-UV) light and $12 \mathrm{~h}$ of dark for 3 days. Sterile distilled water $(20 \mathrm{ml})$ was poured on each plate. Mycelial suspensions obtained were filtered through a 40-mm nylon mesh to remove large mycelial masses that might clog the atomizer. A 4\% (wt/vol) gelatin solution (20 $\mathrm{ml}$ ) was added to the suspension.

For all pathogenicity tests, 30- to 40day-old plants of line IRBB7 growing on steam-sterilized soil were used. IRBB7 was selected as the test plant, because it was the most susceptible among the various lines and modern cultivars previously screened (L. F. Tisalona and T. W. Mew, unpublished). Each plant was fertilized with urea at approximately 150 to $175 \mathrm{~kg}$ $\mathrm{N} \mathrm{ha}{ }^{-1}$. Pathogenicity tests were done for all the collected fungal isolates with one representative isolate of all the collected strains. Approximately 250 fungal isolates were tested. Plants were enclosed with mylar film and then uniformly inoculated until runoff with a deVilbiss atomizer, maintaining constant pressure. Control plants were similarly treated with $4 \%$ gelatin solution. Three to four plants were inoculated for each isolate and the control. To enhance disease development, inoculated plants were sprayed with water to ensure high relative humidity and extend the leaf wetness duration. Inoculated plants were maintained in a shaded area with a mean temperature of $27^{\circ} \mathrm{C}$ (minimum $=22^{\circ} \mathrm{C}$, maximum $=$ $33^{\circ} \mathrm{C}$ ), mean relative humidity of $80 \%$ $($ minimum $=46 \%$, maximum $=98 \%)$, and mean light intensity from 0630 to 1800 hours $(\mathrm{H})$ of $312 \mu \mathrm{mol} \mathrm{m} \mathrm{m}^{-2} \mathrm{~s}^{-1}$ (minimum = $0.675 \mu \mathrm{mol} \mathrm{m} \mathrm{m}^{-2} \mathrm{~s}^{-1}$, maximum $=1063 \mu \mathrm{mol}$ $\mathrm{m}^{-2} \mathrm{~s}^{-1}$ ) during the test period. Plants were sprayed with water until runoff at 1000 , 1200 , and $1400 \mathrm{H}$ each day. A third spray was made between 1600 and $1800 \mathrm{H}$ to keep the plants wet at night. Observations were made every other day starting 14 days after inoculation. This schedule was based on the results of previous experiments which showed that lesions can be observed 14 days after placing a healthy plant in the middle of infected plants (14).

Isolation of bacteria. Sections of 2 to 5 $\mathrm{mm}$ were cut from the margin of an in-

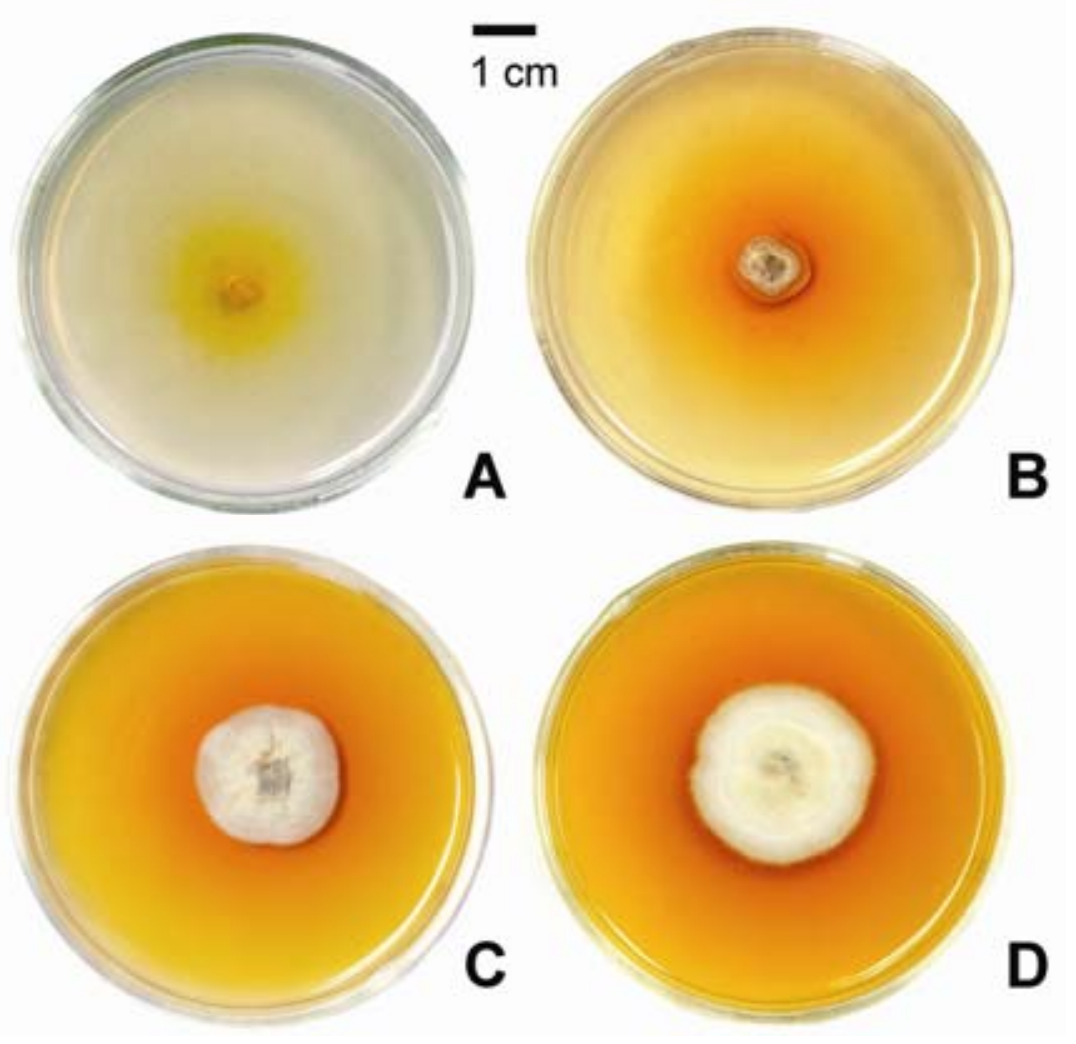

Fig. 2. Colonies and pigmentation of Gonatophragmium sp. grown for A, 3, B, 9, C, 16, and D, 21 days in the dark at 28 to $30^{\circ} \mathrm{C}$ on potato dextrose agar.

fected leaf and surface sterilized as described previously. In all, 20 to 30 leaf sections of each lesion type were placed in a sterile mortar, and $3 \mathrm{ml}$ of sterile distilled water, saline solution, or phosphate buffer solution was added, and the leaf sections were crushed using a sterile pestle. Each solution was serially diluted to $10^{-7}$ dilution and $0.1 \mathrm{ml}$ from each dilution was spread on the surface of different culture media using an L-shaped glass rod. The plates were inverted and incubated for 15 days at $30^{\circ} \mathrm{C}$ in the dark and examined every 2 to 3 days for bacterial colonies. Five to six plates were used for every solution and culture medium. The culture media used were King's B medium, nutrient agar, nutrient broth-yeast extract agar, peptone-sucrose agar (PSA), trypticase soy broth agar, malt extract agar, and modified Wakimoto's medium. The resulting bacterial colonies were transferred to slants of the same culture medium from which they were collected and kept at $5^{\circ} \mathrm{C}$ in continuous darkness until further use.

The cut ends of infected leaves were observed for the presence of bacterial ooze under a stereomicroscope.

Pathogenicity tests for bacterial isolates. Inoculum was prepared by streaking each bacterial isolate on a newly prepared PSA slant. A total of 110 bacterial isolates were tested. After incubating the slants at 28 to $30^{\circ} \mathrm{C}$ for $48 \mathrm{~h}, 10 \mathrm{ml}$ of sterile distilled water was added to each test tube. The bacterial suspension was homogenized using a rotary shaker at approximately 200 rotations per min for 5 to $6 \mathrm{~s}$ at room temperature.

Inoculations were performed by (i) spraying of bacterial suspension of each isolate on injured (using a pin-prick inoculator) and noninjured leaves using a deVilbiss atomizer as described previously and (ii) injecting with bacterial suspensions using a 1-ml sterile disposable syringe with a 22-gauge needle into sheaths and the abaxial side of the midrib of the second or third youngest leaves of a rice plant until fluid dripped out of the tissues. Pathogenicity tests were done for one representative of all the collected isolates. For each method, sterile distilled water was used for control plants. Inoculated plants were maintained and sprayed with water as described for fungal pathogenicity tests.

Fulfillment of Koch's postulates. To fulfill Koch's postulates, the fungus was reisolated from the inoculated leaves showing symptoms similar to those of red stripe following the procedure previously described. During reisolation, a set of leaf samples was left unsterilized to test the effect of sterilization on the success of isolating the pathogen. Inoculation and pathogenicity tests were done as described previously.

Identification and description of the fungus. The red stripe pathogen was identified based on cultural and morphological characteristics of the fungal structures 
grown on PDA $(1,7,8,16)$. Conidia and conidiophores were described and measured.

Sporulation. After fulfilling Koch's postulates, various methods to induce sporulation were used. Blocks of mycelial growth were transferred to petri plates with different culture media. Four methods of inducing sporulation were used. In the first method, the plates were incubated at 28 to $30^{\circ} \mathrm{C}$ for 3 days. Mycelial growth was scraped using a sterile glass slide after 7 to 10 days. Half of the culture plates were incubated under different light conditions with the cover, while the other half were incubated without the cover. In the second method, the culture plates were exposed to different light conditions immediately after mycelia were transferred to the plates. After 5 to 6 days, mycelial growth was scraped, the covers of the petri plates removed, and plates exposed to different light conditions described below. For the first and second methods, the culture media tested were carrot agar, coconut water agar, Czapek's agar, Leonian agar, prune agar, rabbit food agar, rice grain decoction agar, rice leaf decoction agar, rice polished agar, and water agar. For these methods, the different light treatments were as follows: (i) alternate cycle of $12 \mathrm{~h}$ of fluorescent light and $12 \mathrm{~h}$ of dark, (ii) alternate cycle of $12 \mathrm{~h}$ of near-UV light and $12 \mathrm{~h}$ of dark, (iii) $24 \mathrm{~h}$ of darkness (kept in the incubator), and (iv) $12 \mathrm{~h}$ of fluorescent light and $12 \mathrm{~h}$ of dark (kept in Percival growth chamber). Near-UV light consisted of two near-UV light tubes (Philips TLD 36W/08) and one white tube (Philips TL 40W/54/RS, Daylight). The light tubes were placed $9 \mathrm{~cm}$ apart and were placed 41 $\mathrm{cm}$ above the culture plates. Temperature during incubation ranged from 28 to $30^{\circ} \mathrm{C}$. In the third method, mycelial growth from PDA slants was transferred to petri plates with different culture media. The culture media used were carrot agar, oat agar, malt agar, and tap water agar with rice straw $(\mathrm{TWA}+\mathrm{R})$. TWA+R was prepared by adding cut rice straws to tap water agar medium (17). The petri plates then were sealed with Parafilm to prevent rapid drying and were exposed to an alternating cycle of $12 \mathrm{~h}$ of "black light" and $12 \mathrm{~h}$ of dark. The black light consisted of one near-UV light tube placed between two white tubes. The fourth method is similar to the third method, except that culture plates were kept in an incubator that had continuous darkness and temperature of 28 to $30^{\circ} \mathrm{C}$. The fifth method was the blotter method as described previously. The culture plates also were kept in the incubator. Observations were done daily beginning 3 days after incubation.

To determine whether conidial and mycelial suspensions from $\mathrm{TWA}+\mathrm{R}$ medium can produce typical red stripe symptoms, 60 fungal isolates collected from farmers' fields were cultured on TWA+R medium.
Inoculation was done as described for the pathogenicity test of fungal isolates.

\section{RESULTS}

Isolation. A variety of bacterial and fungal isolates were collected and tested using the different methods. Only one fungal isolate, which was obtained using the blotter test method, produced typical red stripe symptoms and the same fungus was isolated from the typical lesions of red stripe. This isolate was designated as isolate PRS37. Inoculations were made with the reisolated fungus and similar disease symptoms were once again produced, thus fulfilling Koch's postulates.
Symptomatology and disease development. Typical lesions on leaves that were artificially inoculated with the isolate PRS37 were categorized into four types (Fig. 1C). The initial lesion, which was designated as type 1, appeared as a round, water-soaked, pinhead-sized spot of about $1 \mathrm{~mm}^{2}$, often greenish yellow to yellow. Initial lesions were more apparent when observed from the abaxial side of the leaf The lesions grew to yellow-orange elliptical spots 2 to $5 \mathrm{~mm}$ long with an average area of $5 \mathrm{~mm}^{2}$ (type 2). The lesions increased further to an average length of about $5 \mathrm{~mm}$ and an average area of about $12 \mathrm{~mm}^{2}$, and produced greenish-yellow or
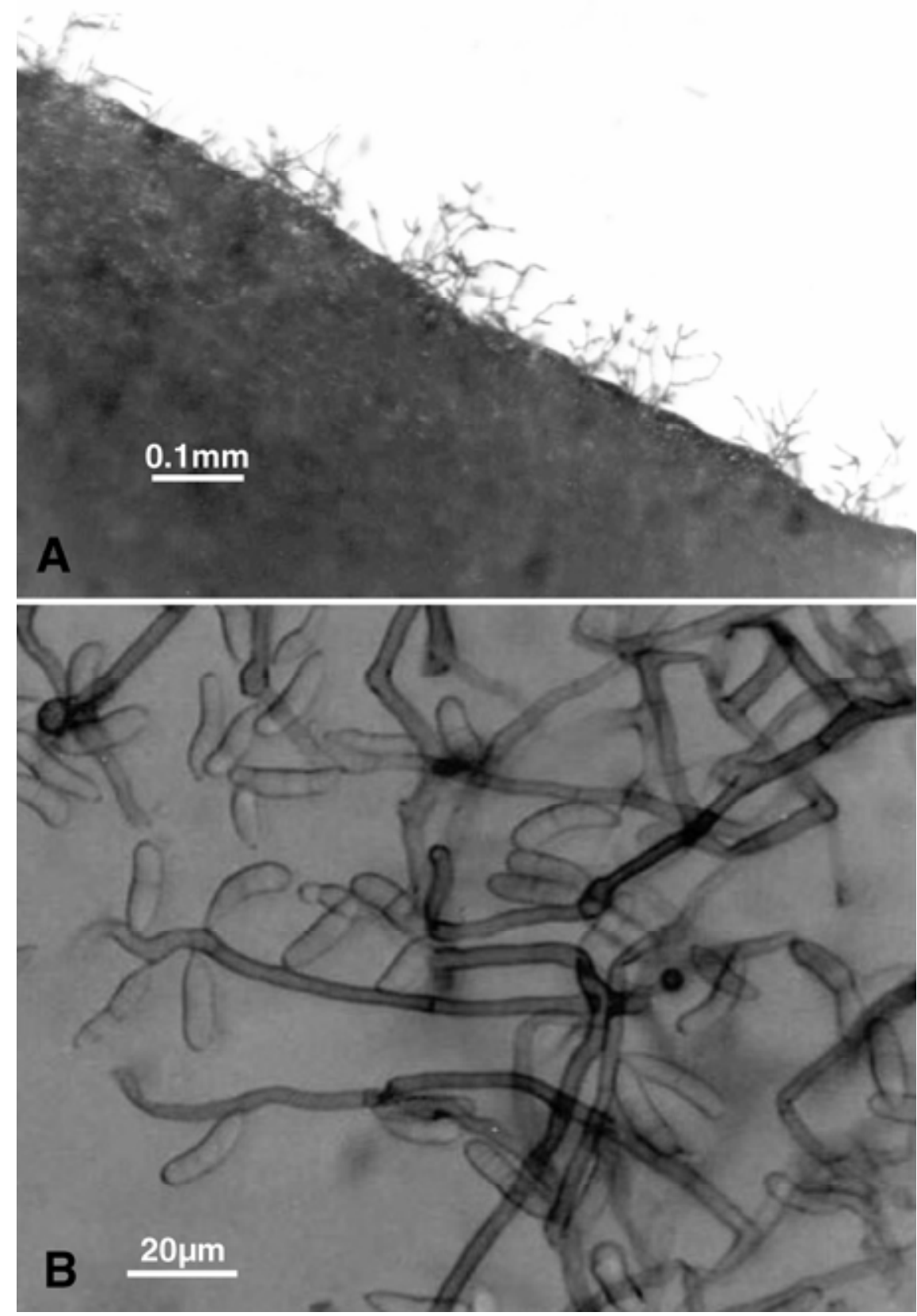

Fig. 3. A, Habit and B, morphological characters of Gonatophragmium sp. (isolate PRS37) on plated tap water agar with rice straw medium. 
yellow, narrow streaks that advanced to the tip of a leaf (type 3). A mature lesion, which had an average length of about 6 $\mathrm{mm}$ and an average area of about $22 \mathrm{~mm}^{2}$, had a yellow-orange streak that usually was more distinct and wider than that of type 3 . This lesion type, which usually was observed in the field, was designated as type 4 . These four lesion types also were observed on infected plants found in farmers' fields. Mature lesions on inoculated plants became necrotic and had a grayish center. Initial lesions were observed on the test plants starting 6 days after inoculation, whereas mature lesions were more common 14 days after inoculation. The concentration of inocula used in pathogenicity tests produced several lesions on a leaf, which later coalesced and resulted in the wilting of some leaves. Lesions also were observed on the leaf sheath and culm (Fig. 1D and E).

Characteristics of mycelial growth of the causal fungus. Colonies of isolate PRS37 on PDA were composed of dense, slow-growing mycelium reaching an aver- age of $29.0 \pm 0.9 \mathrm{~mm}$ in diameter after incubation for 18 days at 28 to $30^{\circ} \mathrm{C}$ in the dark. Colonies had creamy-white to brownish-white entire, circular, fine mycelial growth at the center and velvety grayish growth at the border, with even margin and umbonate elevation. Mycelia were velvety and azonate when young, becoming zonated and powdery in age. Zonation and radial furrows were observed on colonies grown for 14 days or longer. Brown mycelial tufts were observed in some plates. Stroma was absent. On the reverse

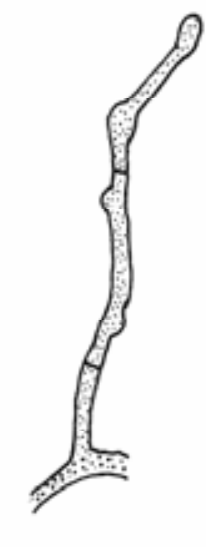

A
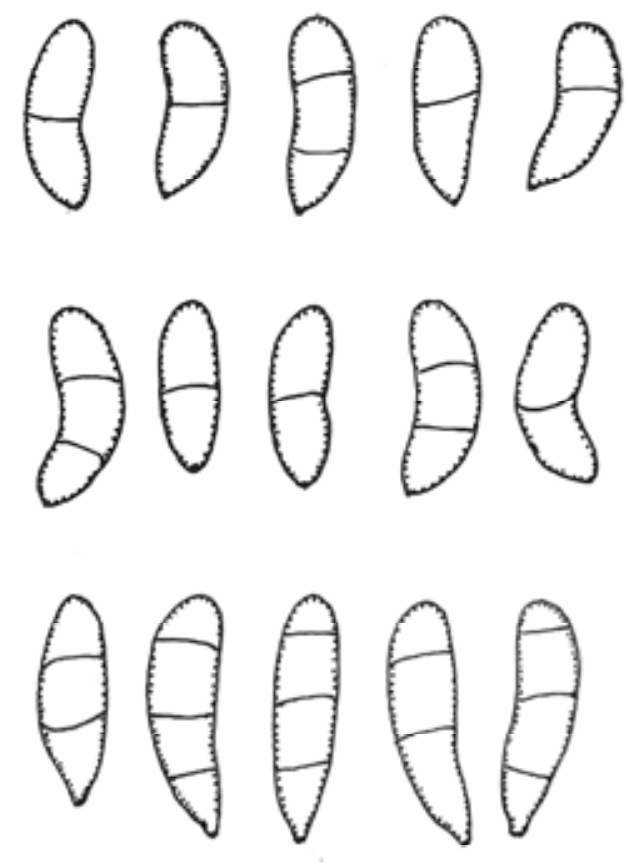

C
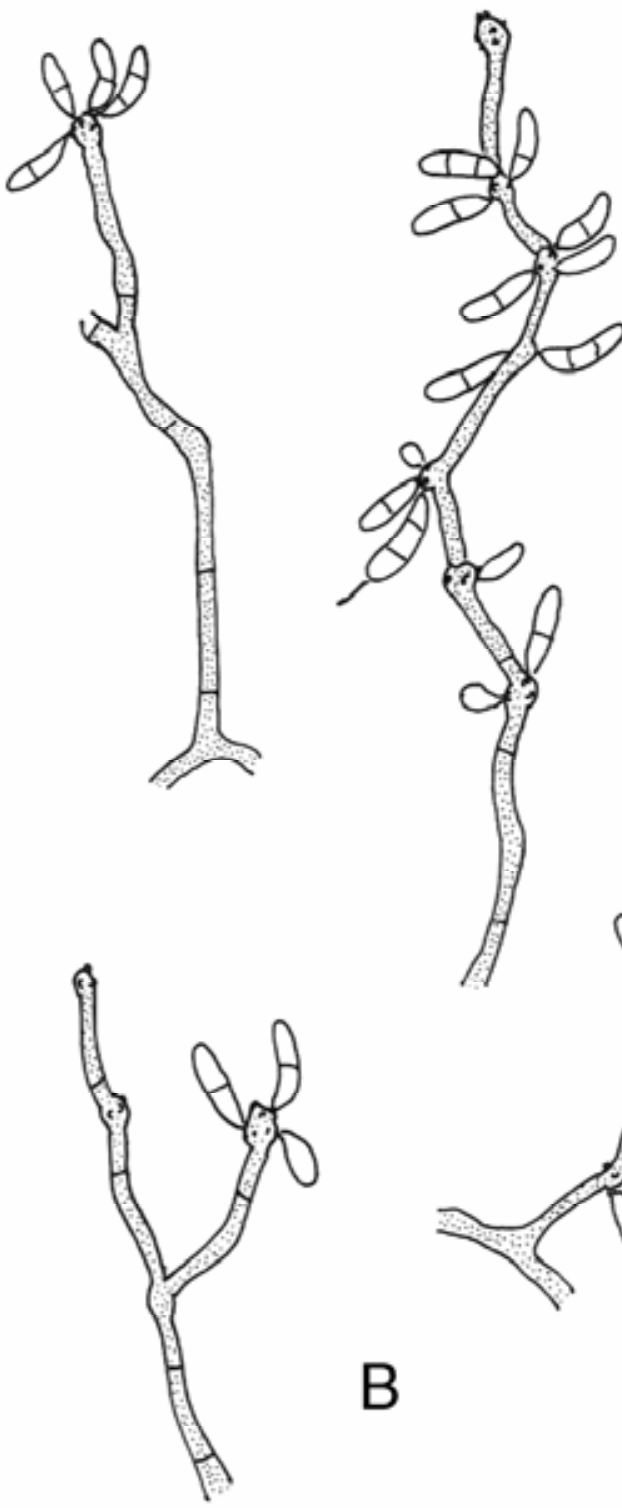

B
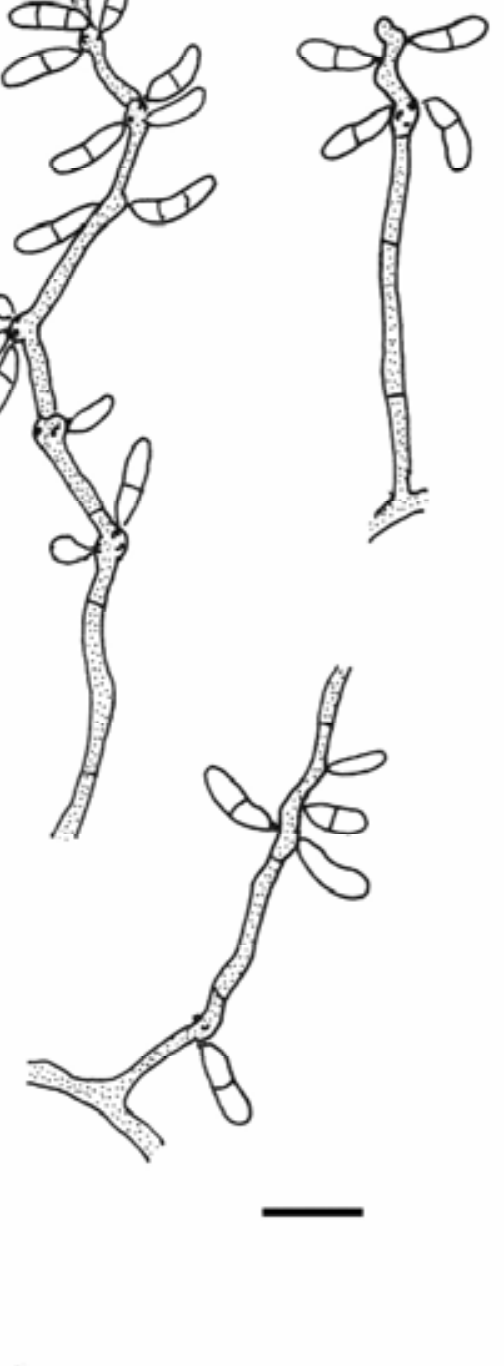

Fig. 4. Diagrammatic representation of Gonatophragmium sp. (isolate PRS37). A, Conidiophores showing nodose swellings, B, conidia arising from nodes and swollen ends of the conidiophores, and $\mathbf{C}$, conidia. Scale bar: A and B $=20 \mu \mathrm{m}, \mathrm{C}=10 \mu \mathrm{m}$. 
of the PDA plate, colonies were zonated with radial wrinkles and brown to dull brown. Faint pigmentation was observed near the colony 1 day after incubation. A more distinct yellow-orange to orange pigmentation was observed starting 2 days after incubation. The intensity of the pigment increased with the incubation period (Fig. 2).

Characteristics of conidiophores and conidia. Conidiophores were smooth, flexuous, pale brown to olive brown, branched, and septate, with nodose swellings which often proliferated as lateral branches arising terminally and laterally from the mycelium, and measured up to $500 \mu \mathrm{m}$ long and 2.5 to $5.0 \mu \mathrm{m}$ wide (Figs. 3 and 4). The conidiophores produced on TWA + R medium and leaf tissues were 5 to $9 \mu \mathrm{m}$ wide. Conidiogenous cells were integrated, polyblastic, sympodial, apical and intercalary, denticulate, smooth, and subhyaline to pale brown (Fig. 5). Conidia were solitary, dry, smooth, pale to midbrown, straight to distinctly curved, clavate cylindrical to obclavate, acropleurogenous, apex obtuse, and base tapered, with one to three transverse septa, occasionally with setulae, and measured 10 to 48 by 2 to 14 $\mu \mathrm{m}$ (Figs. 3 and 4). Those produced on infected leaves in moist chambers were larger than those on artificial media, ranging from 20 to $48 \mu \mathrm{m}$ by 7 to $14 \mu \mathrm{m}$, and with an average of 30 by $10 \mu \mathrm{m}$. Based on these morphological characters, the causal fungus of red stripe was identified as a species of Gonatophragmium Deighton. Studies are in progress to identify the species.

Collection of new isolates. To date, we have been able to isolate the causal fungus of red stripe only using the blotter method. To verify the effectiveness of this method, a new batch of infected leaves was collected from farmers' fields. The morphology and pigmentation of the collected isolates were compared with those of isolate PRS37. In all, 208 isolates that resembled isolate PRS37 were collected from surface-sterilized leaves. The isolates also produced pigments on PDA and filter papers similar to that produced by isolate PRS37. Some isolates were obtained from lesion types 1 and 2, but most of the isolates were obtained from lesion types 3 and 4. Pathogenicity tests of 60 isolates that represented different lesion types all were positive. The pathogen was not isolated from lesions of unsterilized leaves, and saprophytic fungi that commonly are associated with rice were isolated instead. The most common saprophytes, in decreasing order, were species of Nigrospora, Curvularia, and Cercospora.

Sporulation. Among the various media tested, TWA+R was the only medium which induced sporulation within the 14day observation period. Conidia were observed starting 6 days after incubation either at an alternating cycle of $12 \mathrm{~h}$ of black light and $12 \mathrm{~h}$ of dark or in continuous darkness in the incubator. Conidia on TWA+R were gray to black (Fig. 3A). Conidia also were produced on leaves that were kept in the incubator using the blotter method. Yellow-orange to orange pigmentation on the filter paper was observed around the leaves starting 3 days of incubation, whereas spores usually were observed about 4 days after the appearance of pigmentation or 7 days after incubation of the infected leaves (Fig. 6). The unique pigmentation was later used as an indicator of the occurrence of conidia on infected leaves, which facilitated succeeding isolations of the pathogen. Leaves contained grayish sporulating lesions.

Conidial and mycelial suspensions prepared from TWA+R cultures produced typical red stripe symptoms on test plants.

\section{DISCUSSION}

Results of previous studies suggested that red stripe is caused by a fungus rather than a bacterial pathogen. The disease can be controlled by farmers in Vietnam using fungicides (12). Moreover, experiments conducted in the field and the greenhouse to determine the efficacy of bactericides
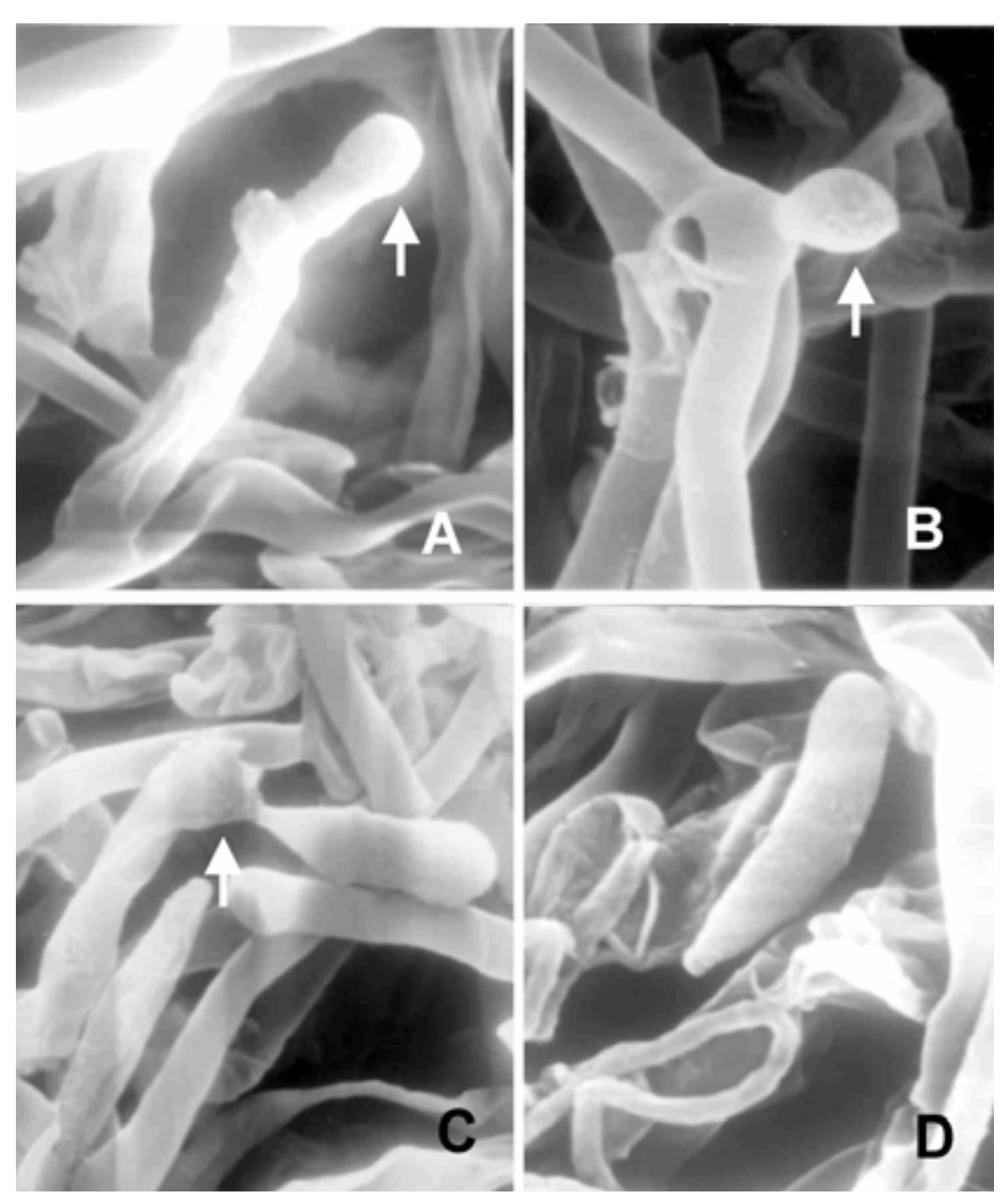

Fig. 5. Scanning electron micrographs of Gonatophragmium sp. (isolate PRS37). A, Developing conidium (with arrow) nearly at the tip of the conidiophore. B, Developing conidium (with arrow) at the nodal swelling along conidiophore. C, Denticulate conidiophore (with arrow) bearing conidia. D, Detached mature conidium. Magnification: $\times 3,000$ to 4,000 . and fungicides showed that only fungicides reduced the disease $(4,11,14)$. Nevertheless, we initially did not rule out the possibility that red stripe may be caused by bacteria. Earlier studies suggested that the pathogen is not associated with viruses or mycoplasma-like organisms. Transmission and electron microscopy studies conducted at IRRI showed neither any viruses nor mycoplasma-like organisms (14). Other scientists also examined sections of infected leaves under the transmission electron microscope, but did not find virus-like particles (21). In our preliminary studies, we did not observe bacterial ooze from cut ends of infected leaves. We collected several bacterial isolates using various methods as described above. However, pathogenicity tests of all the bacterial isolates were negative despite the use of various inoculation methods for bacteria, such as tissue wounding, injection, and spraying of bacterial suspension on healthy leaves. We, therefore, rejected any bacterium as being the causal organism of red stripe.

After determining that bacteria were not involved, we focused on isolating fungi using several natural and synthetic media, and explored various isolation methods.

Plant Disease / December 2004 


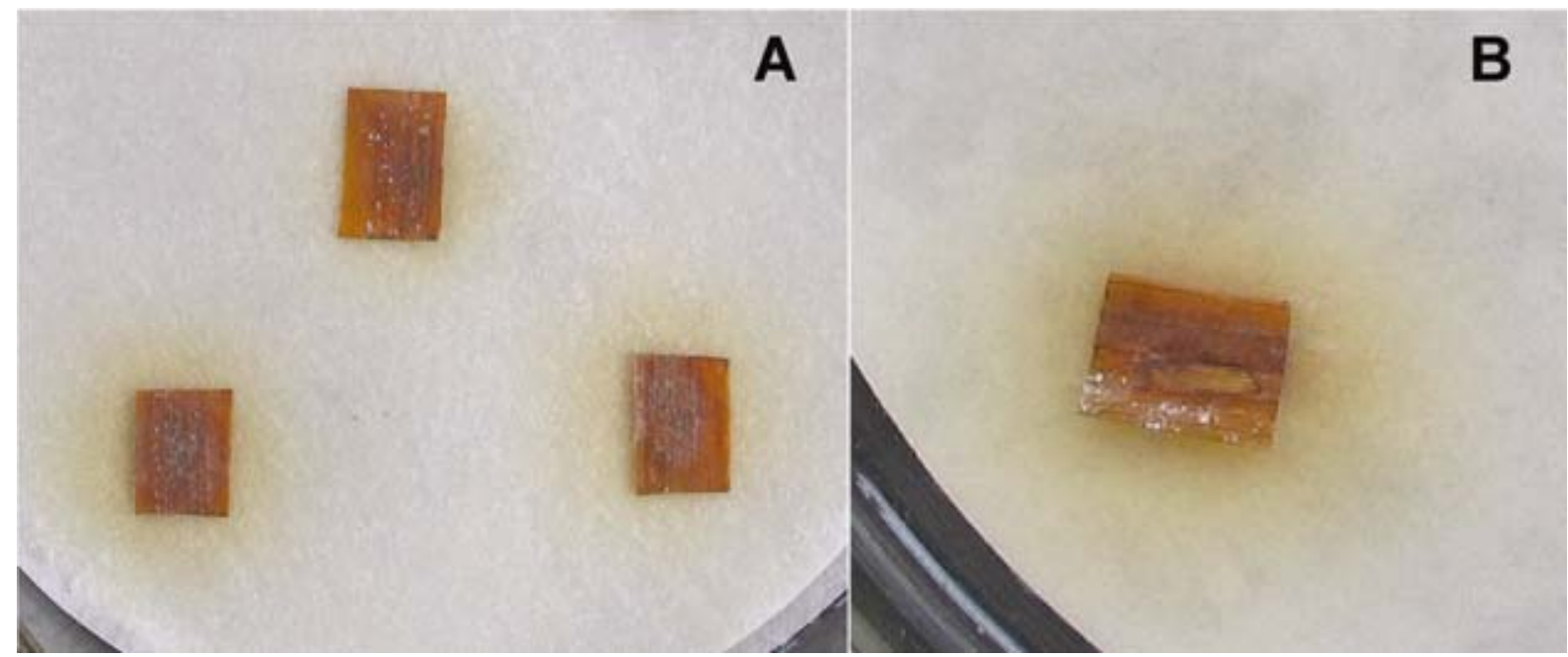

Fig. 6. A, Sections of leaves with sporulating lesions and $\mathbf{B}$, close-up of an infected leaf incubated using blotter method for 7 days at 28 to $30^{\circ} \mathrm{C}$.

We collected several fungal isolates and tested their pathogenicity on plants kept under humid conditions. The fungal pathogen consistently was isolated from surfacesterilized, infected leaves using the blotter method. Our results suggest that there are two critical parameters for the successful isolation of the pathogen. The first is the suppression of the growth of saprophytes. It appears that the difficulty in isolating the red stripe pathogen can be partly attributed to its slow growth on culture media and to the fact that it can be easily outgrown by saprophytes using the conventional tissueplating method. Placement of infected leaves on culture media probably provided nutrients that promoted the growth of faster-growing saprophytes and other microorganisms despite the surface sterilization of infected leaves. Other workers also reported the isolation of saprophytic fungi from infected leaf tissues with the use of different culture media $(5,18,21)$. We also failed to isolate the pathogen from unsterilized leaves using the blotter method because saprohytes outgrew the pathogen. The other critical parameter in the isolation of the pathogen is timing of picking the conidia from infected leaves. Conidia developed starting 7 days after the incubation of infected leaves at $30^{\circ} \mathrm{C}$ using the blotter method. Our initial attempts to isolate the pathogen using this method failed because we discontinued our observations after the leaves were incubated for 4 days.

The production of yellow-orange to orange pigment on the filter paper around infected leaves, and on PDA with mycelial growth, is a unique characteristic that distinguishes the red stripe pathogen from other fungal pathogens of rice. This characteristic has facilitated succeeding isolations of the pathogen, because it served not only as an indicator for the presence and growth of the pathogen, but it also helped us know when to pick hyphal tips and conidia. The pigment might be a toxin produced by the pathogen. Considering the similarity in color between the pigment and the streak of mature lesions, the pigment could be a toxin associated with the streak that develops from type 3 and type 4 lesions. The streak always advances toward the tips of the leaves in both naturally and artificially infected plants; therefore, the toxin probably is water soluble and mobile within the xylem.

Production of red stripe lesions using inoculum consisting of mycelial suspensions only demonstrates that fungal hyphae could infect plant tissues.

Studies on the identification of the red stripe pathogen at the species level using traditional and molecular techniques are in progress. The pathogen may be a new species because its morphology differs from that of previously described species of Gonatophragmium. Although the species is not yet known, establishing that the red stripe disease is caused by a fungal pathogen will greatly facilitate research work on disease epidemiology and development of disease management strategies.

\section{ACKNOWLEDGMENTS}

We thank M. Banasihan, Research Technician of the Entomology and Plant Pathology Division of IRRI, for technical expertise in assisting us in the collection of infected leaves, and in the isolation, cultivation, and testing of the pathogenicity of all the isolates; and P. Gonzales, Assistant Scientist of the Seed Health Unit of IRRI, for helping us identify and describe the red stripe fungus.

\section{LITERATURE CITED}

1. Barnett, H. L., and Hunter, B. B. 1972. Illustrated Genera of Imperfect Fungi. Burgess Publishing Company, Minneapolis, MN.

2. Barroga, J. F., and Mew, T. W. 1994. "Red stripe": a new disease of rice in the Philippines. (Abstr.) Pages 83-84 in: Anniv. Ann. Sci. Conv. Pest Manage. Counc. Philipp. 25th, Cagayan de Oro City, Philippines.

3. Dhitikiattipong R., Nilpanit N., Surin, A., Arunyanart, P., and Chettanachit, D. 2001. Red stripe in Thailand. Pages 41-43 in: Proc. Planning Workshop on Red Stripe. T. W. Mew, ed. International Rice Research Institute, Los Baños, Philippines.

4. Du, P. V., Dinh, H. D., Lan, N. T. P., Sau, T. T., and Ba, D. X. 1991. Field evaluation to control "red stripe", a new rice disease in Vietnam. Int. Rice Res. Newsl. 16(5):21-22.

5. Du, P. V., Lan, N. T. P., and Dinh, H. D. 1991. Red stripe, a newly reported disease of rice in Vietnam. Int. Rice Res. Newsl. 16(3):25.

6. Du, P. V., Noda, T., and Lai, V. E. 2001. Studies on some aspects of red stripe disease of rice in the Mekong Delta. Pages 15-20 in: Proc. Planning Workshop Red Stripe. T. W. Mew, ed. International Rice Research Institute, Los Baños, Philippines.

7. Ellis, M. B. 1971. Dematiaceous Hyphomycetes. Commonwealth Mycological Institute, Kew, Surrey, England.

8. Ellis, M. B. 1976. More Dematiaceous Hyphomycetes. Commonwealth Mycological Institute, Kew, Surrey, England.

9. Kaku, H., Subandiyah, S., and Ochiai, H. 2000. Red stripe of rice is caused by a bacterium Microbacterium sp. J. Gen. Plant Pathol. 66:149-152.

10. Karganilla, A., Paris-Natural, M., and Ou, S. H. 1973. A comparative study of culture media for Xanthomonas oryzae. Philipp. Agric. 57:141-152

11. Kim, P. V., and Bien, P. V. 2000. Review on results of studying on red stripe disease of rice at south Vietnam. (Abstr.) Proc. Asian Conf. Plant Pathol. 1st, Beijing, China.

12. Mai, V., Huan, N. H., Heong, K. L., Escalada, M. M., and Lazaro, A. A. 1997. Pest management perceptions and practices of rice farmers in Long An province, Vietnam. Pages 213-225 in: Pest Management of Rice Farmers in Asia. K. L. Heong and M. M. Escalada, eds. International Rice Research Institute, Manila, Philippines.

13. Mathur, S. B., and Kongsdal, O. 2003. Common Laboratory Seed Health Testing Methods for Detecting Fungi. International Seed Testing Association, Bassersdorf, Switzerland.

14. Mew, T. W., Castilla, N. P., Elazegui, F. A., and Vera Cruz, C. M. 2001. The etiology of red stripe of rice, current status and future directions. Int. Rice Res. Notes 26(1):4-10.

15. Mogi, S., Sugandhi, Z., and Baskoro, S. 1988. A new discovered disease (bacterial red stripe) on rice at Indonesia, its symptoms and distribution. (Abstr.) Int. Congr. Plant Pathol. 5th, Kyoto, Japan.

16. Quimio, T. H., and Hanlin, R. T. 1999. Illustrated Genera and Species of Plant Pathogenic Fungi in the Tropics. University of the Philippines College of Agriculture, Los Baños, Philippines.

17. Ritchie, B. J. 2002. Mycological media and methods. Pages 410-431 in: Plant Pathologist's 
Pocketbook. J. M. Waller, H. M. Lenné, and S. J. Waller, eds. CABI Publishing, Wallingford, Oxon, UK

18. Saad, A. 2001. The occurrence of red-stripe disease in Malaysia. Pages 37-40 in: Proc. Planning Workshop on Red Stripe. T. W. Mew, ed. International Rice Research Institute, Los Baños, Philippines.
19. Suparyono. 2001. Bacterial orange leaf blight of rice in Indonesia. Pages 33-35 in: Proc. Planning Workshop on Red Stripe. T. W. Mew, ed. International Rice Research Institute, Los Baños, Philippines.

20. Tuat, N. V. 2001. Red stripe and associated diseases in Vietnam. Pages 25-28 in: Proc. Planning Workshop on Red Stripe. T. W. Mew, ed. International Rice Research Institute, Los Baños, Philippines.

21. Vinh, M. T, Mew, T. W., and Bien, P. V. 2001 Etiological studies on the yellow leaf syndrome of rice (Oryza sativa L.). Pages 3-13 in: Proc. Planning Workshop on Red Stripe. T. W. Mew, ed. International Rice Research Institute, Los Baños, Philippines. 